\title{
Decolorization of RhB dye by manganese oxides: effect of crystal type and solution $\mathrm{pH}$
}

\author{
Hao-Jie Cui ${ }^{1}$, Hai-Zheng Huang ${ }^{2}$, Baoling Yuan ${ }^{3}$ and Ming-Lai Fu ${ }^{1 *}$
}

\begin{abstract}
Background: Organic dye pollution in water has become a major source of environmental pollution. Mn(III/IV) oxides have attracted a great deal of attention to remove organic dye pollutants due to their unique structures and physicochemical properties. Numerous studies have reported the removal of dye by various Mn(III/IV) oxides through catalytic degradation and adsorption. The crystalline structures of manganese oxides and solution pH may exert substantial impact on the removal of dyes. However, few studies have focused on the oxidative degradation of RhB dye using Mn(III/IV) oxides with different crystal structures during a spontaneous reaction. In the present study, three manganese oxides with different crystal type $\left(\alpha-\mathrm{MnO}_{2}, \beta-\mathrm{MnO}_{2}\right.$, and $\left.\delta-\mathrm{MnO}_{2}\right)$ were prepared by refluxing process to decolorize RhB dye in various $\mathrm{pH}$ solutions.

Results: The results showed that the decolorization efficiencies of $\mathrm{RhB}$ for the three manganese oxides all increase with decrease solution $\mathrm{pH} . \alpha-\mathrm{MnO}_{2}$ exhibited highest activity and could efficiently degrade $\mathrm{RhB}$ at $\mathrm{pH} 2-6$. The degradation of $\mathrm{RhB}$ by $\beta-\mathrm{MnO}_{2}$ and $\delta-\mathrm{MnO}_{2}$ could be observed at $\mathrm{pH} 2-3$, and only little adsorption $\mathrm{RhB}$ on manganese oxides could be found at $\mathrm{pH} 4-6$. The UPLC/MS analysis suggests that the decolorization of RhB by manganese oxides consists of three main stages: (1) cleavage of the ethyl groups from RhB molecular to form Rh; (2) further destruction of $-\mathrm{COOH}$ and $-\mathrm{CNH}_{2}$ from Rh to form the small molecular substances; (3) mineralization of the small molecular substances into $\mathrm{CO}_{2}, \mathrm{H}_{2} \mathrm{O}, \mathrm{NO}_{3}{ }^{-}$and $\mathrm{NH}_{4}{ }^{+}$.
\end{abstract}

Conclusions: Overall, these results indicate that $\alpha-\mathrm{MnO}_{2}$ may be envisaged as efficient oxidants for the treatment of organic dye-containing wastewater under acid conditions.

Keywords: RhB, Manganese oxides, Crystal structure, Solution pH, Oxidation

\section{Background}

Nowadays, organic dye pollution in water has become a major source of environmental pollution due to the fast development of dye industry $[1,2]$. Discharging of the residual dyes creates acute problems to the ecosystem and human health [3]. For example, Rhodamine B (RhB), as an important cationic xanthene dye (Scheme 1), has been extensively used in textile, printing, and photographic industries. It has been found to possess carcinogenicity, neurotoxicity, and chronic toxicity towards

\footnotetext{
*Correspondence: mlfu@iue.ac.cn

${ }^{1}$ Institute of Urban Environment, Chinese Academy of Sciences,

Xiamen 361021, China

Full list of author information is available at the end of the article
}

humans and animals [4]. Therefore, it is necessary to destroy the dyes from industrial effluents before they become detrimental to the natural environments.

In the recent years, $\mathrm{Mn}(\mathrm{III} / \mathrm{IV})$ oxides have attracted a great deal of attention to remove organic dye pollutants due to their unique structures and physicochemical properties [5-7]. The removal efficiencies of the dye pollutants by $\mathrm{Mn}(\mathrm{III} / \mathrm{IV})$ oxides are dependent upon their crystallographic forms, which could display layered or tunnel structures through different arrangements of $\mathrm{MnO}_{6}$ octahedra $[8,9]$. Up to now, numerous studies have reported the removal of dye by various $\mathrm{Mn}(\mathrm{III} / \mathrm{IV})$ oxides through catalytic degradation and adsorption [5, 10-12]. Few studies have focused on the oxidative degradation of $\mathrm{RhB}$ 


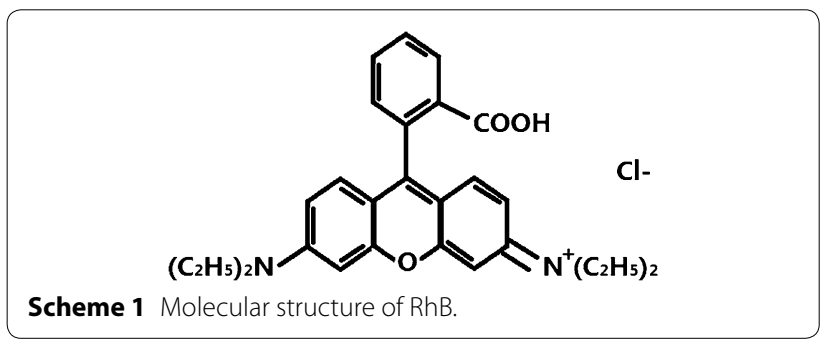

using $\mathrm{Mn}(\mathrm{III} / \mathrm{IV})$ oxides with different crystal structures during a spontaneous reaction. Moreover, as reported in the previous literatures, the $\mathrm{Mn}(\mathrm{III} / \mathrm{IV})$ oxides were commonly prepared by different methods including refluxing process, hydrothermal method, and calcination method [12-14]. The Mn(III/IV) oxides prepared using different methods often display different reactivity.

In the present work, three $\mathrm{Mn}(\mathrm{III} / \mathrm{IV})$ manganese oxides $\left(\alpha-\mathrm{MnO}_{2}, \beta-\mathrm{MnO}_{2}\right.$, and $\left.\delta-\mathrm{MnO}_{2}\right)$ with different crystal structures were prepared by similar refluxing process, and the products were used to decolorize $\mathrm{RhB}$ in various $\mathrm{pH}$ solutions to investigate the effects of crystal type of manganese oxides and solution $\mathrm{pH}$ on the removal efficiencies and mechanisms of $\mathrm{RhB}$ dye from waters.

\section{Results and discussion}

\section{Characterizations of the synthetic manganese oxides}

Figure 1a shows the XRD patterns of the as-prepared manganese oxides. All the diffraction peaks could be readily indexed to $\alpha-\mathrm{MnO}_{2}$ (JCPDS 44-1386), $\beta-\mathrm{MnO}_{2}$ (JCPDS 24-0735) and $\delta-\mathrm{MnO}_{2}$ (JCPDS 80-1098), respectively. The results indicate that purely crystalline $\alpha-\mathrm{MnO}_{2}$, $\beta-\mathrm{MnO}_{2}$ and $\delta-\mathrm{MnO}_{2}$ were successfully synthesized. The SEM images show that the as-prepared $\alpha-\mathrm{MnO}_{2}$ samples consist of needle-like nanostructures with a diameter of $10-30 \mathrm{~nm}$ and a length of 300-1,000 nm (Fig. 1b). The synthetic $\beta-\mathrm{MnO}_{2}$ samples exhibit rod-like shape with a diameter of $50-100 \mathrm{~nm}$ and a length of $200-500 \mathrm{~nm}$ (Fig. 1c). The $\delta-\mathrm{MnO}_{2}$ shows a three dimensional hierarchical microsphere with a diameter ranging from 300 to $500 \mathrm{~nm}$, and the microspheres consist of nanoplates with a thickness of an approximately $10 \mathrm{~nm}$ (Fig. 1d). The BET surface area, average Mn oxidation state (AOS), and the point of zero charge (PZC) of the three manganese
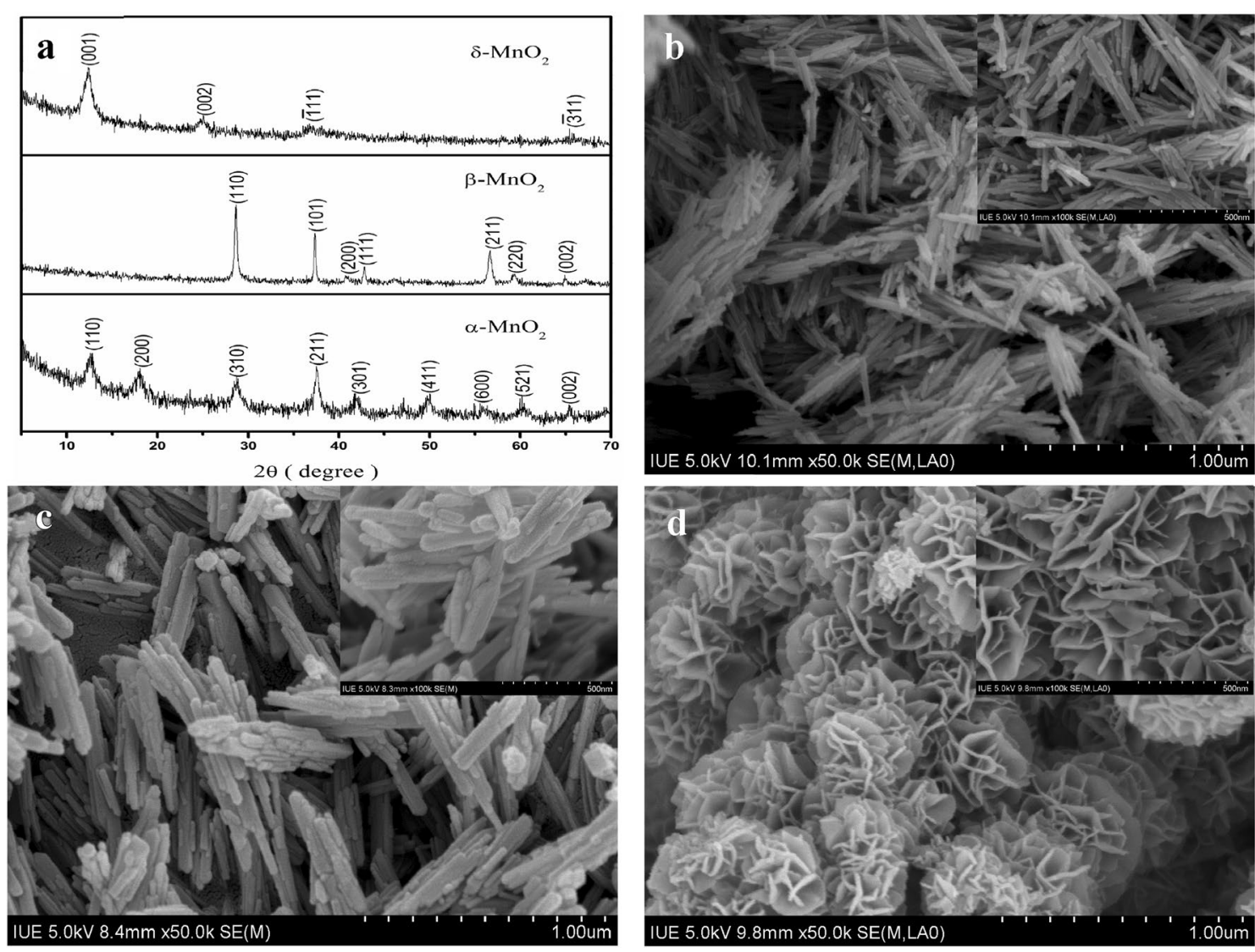

Fig. 1 XRD patterns (a) and SEM images of the synthetic manganese oxides: $\mathbf{b} \alpha-\mathrm{MnO}_{2} ; \mathbf{c} \beta-\mathrm{MnO}_{2} ; \mathbf{d} \delta-\mathrm{MnO}_{2}$. 


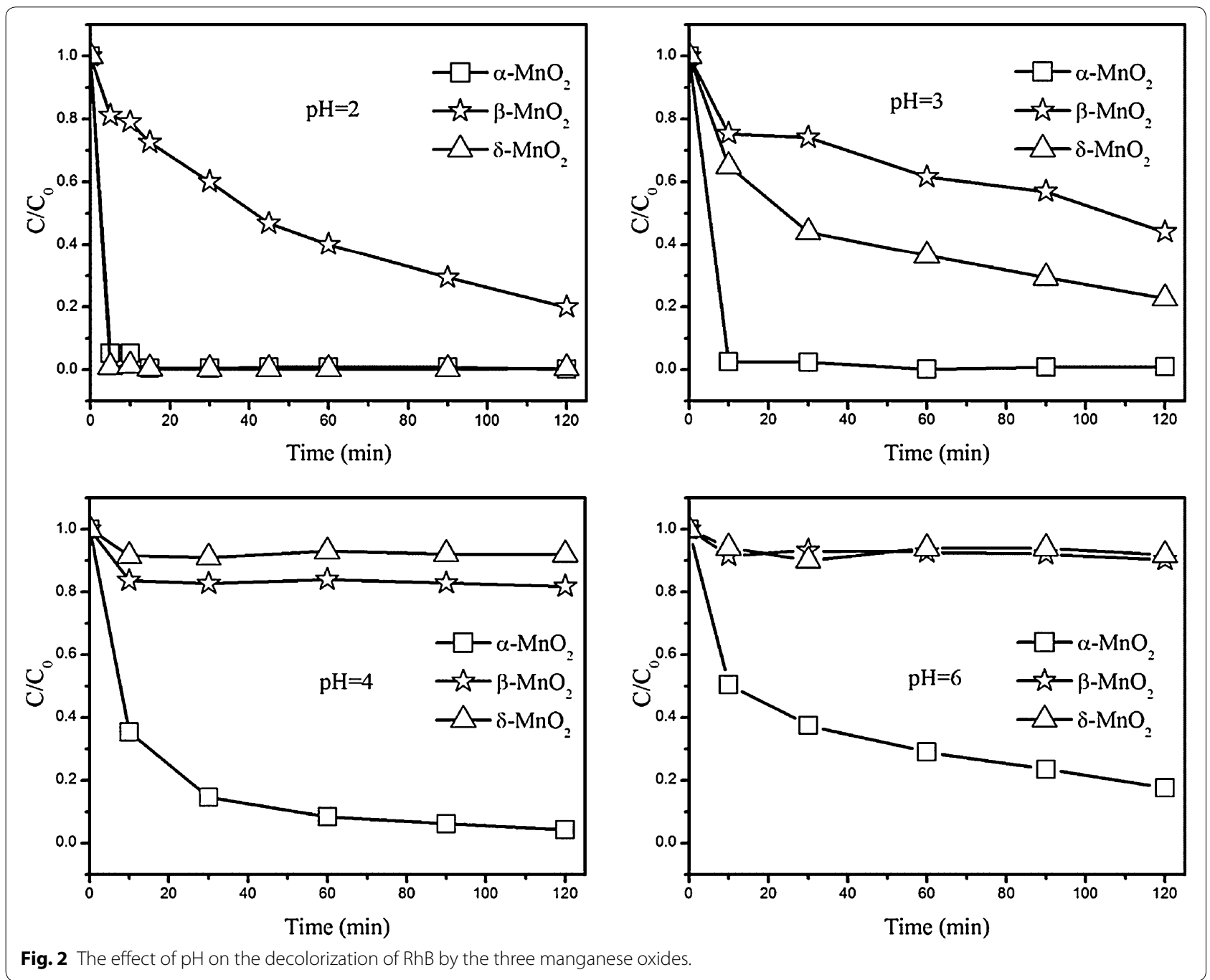

oxides were also characterized and the results were listed in Table 1.

\section{Decolorization of RhB dye by the manganese oxides at various $\mathrm{pH}$ values}

The results for decolorization of RhB dye by the three manganese oxides at different $\mathrm{pH}$ were shown in Fig. 2. In detail, at $\mathrm{pH} 2, \alpha-\mathrm{MnO}_{2}$ and $\delta-\mathrm{MnO}_{2}$ both possessed high efficiency to decolorize $\mathrm{RhB}$, and the degree of

Table 1 Selected properties of the synthetic manganese oxides

\begin{tabular}{llll}
\hline Samples & $\begin{array}{l}\text { BET surface area } \\
\left(\mathbf{m}^{2} / \mathbf{g}\right)\end{array}$ & Mn AOS & PZC \\
\hline$\alpha-\mathrm{MnO}_{2}$ & 83.5 & 3.89 & 4.7 \\
$\beta-\mathrm{MnO}_{2}$ & 27.9 & 3.96 & 3.8 \\
$\delta-\mathrm{MnO}_{2}$ & 40.1 & 3.71 & 3.4 \\
\hline
\end{tabular}

decolorization reached above $90 \%$ within 5 min. However, the decolorization of $\mathrm{RhB}$ by $\beta-\mathrm{MnO}_{2}$ is far slower than that of $\alpha-\mathrm{MnO}_{2}$ and $\delta-\mathrm{MnO}_{2}$, and only about $80 \%$ of initial of $\mathrm{RhB}$ was decolorized within $120 \mathrm{~min}$. At $\mathrm{pH}$ 3 , more than $90 \%$ of the $\mathrm{RhB}$ could be decolorized by $\alpha-\mathrm{MnO}_{2}$ within $10 \mathrm{~min}$, which is much faster than that of $\delta-\mathrm{MnO}_{2}$ and $\beta-\mathrm{MnO}_{2}$. After reaction of $120 \mathrm{~min}$, the decolorization efficiencies of $\mathrm{RhB}$ by $\delta-\mathrm{MnO}_{2}$ and $\beta-\mathrm{MnO}_{2}$ are only about 80 and $50 \%$, respectively. During the reaction at $\mathrm{pH} 4$, only less than $20 \%$ of $\mathrm{RhB}$ could be decolorized by $\delta-\mathrm{MnO}_{2}$ and $\beta-\mathrm{MnO}_{2}$ within $120 \mathrm{~min}$, and the decolorization proceeds with high efficiency is still observed for $\alpha-\mathrm{MnO}_{2}$. Further increasing $\mathrm{pH}$ to 6, no obvious dye decolorization is observed for $\delta-\mathrm{MnO}_{2}$ and $\beta-\mathrm{MnO}_{2}$ after $120 \mathrm{~min}$, the degree of decolorization for $\alpha-\mathrm{MnO}_{2}$ decreased to about $80 \%$. These results indicated that the decolorization efficiency of RhB by manganese oxides depend on the crystal type and solution $\mathrm{pH}$, and 
$\alpha-\mathrm{MnO}_{2}$ presents highest capability to decolorize $\mathrm{RhB}$ in $\mathrm{pH} 2-6$.

UV-vis absorption spectra of the RhB solution treated with the three manganese oxides are shown in Additional file 1: Figure S2. For $\alpha-\mathrm{MnO}_{2}$, the intensity of the $\mathrm{RhB}$ peaks decreased sharply within $5-10 \mathrm{~min}$, and the peak of $554 \mathrm{~nm}$ obviously shifted to $500 \mathrm{~nm}$, which indicates that the decolorization of $\mathrm{RhB}$ by $\alpha-\mathrm{MnO}_{2}$ is mainly attributed to the decomposition reaction at $\mathrm{pH} 2-6[15$, 16]. Meanwhile, the same blue shift of $554 \mathrm{~nm}$ peak was observed at low pHs for $\delta-\mathrm{MnO}_{2}(\mathrm{pH} 2$ and 3) and $\beta-\mathrm{MnO}_{2}(\mathrm{pH} 2)$. However, only a weak decrease of the intensity of the RhB peaks, and no peak shifts were found at $\mathrm{pH} 4$ and $\mathrm{pH} 6$. These results implied that the decomposition reaction only occurs at $\mathrm{pH} \leq 3$ and adsorption is responsible to the decolorization of the $\mathrm{RhB}$ at $\mathrm{pH}>3$. Therefore, the decolorization mechanism of RhB by manganese oxides depends on the crystal type of the oxides and the solution $\mathrm{pH}$.

In this investigation, the three crystallographic $\mathrm{MnO}_{2}$ showed different activities for RhB degradation, which can be related to the variation in crystalline structure, AOS, BET surface area and other physicochemical properties. At low pHs, the crystal stability of the layered structure of $\delta-\mathrm{MnO}_{2}$ is weaker than that of the tunnel structures of $\alpha-\mathrm{MnO}_{2}$ and $\beta-\mathrm{MnO}_{2}$, which is beneficial to the redox reaction between $\mathrm{Mn}(\mathrm{VI} / \mathrm{III})$ and $\mathrm{RhB}$. This may account for its faster oxidization of $\mathrm{RhB}$ at $\mathrm{pH}$ 2 than $\alpha-\mathrm{MnO}_{2}$ and $\beta-\mathrm{MnO}_{2}$. With increasing solution $\mathrm{pH}$ to 4 , the adsorption became fully responsive to the decolorization of $\mathrm{RhB}$ for $\delta-\mathrm{MnO}_{2}$. However, the oxidation of RhB still could be found for $\alpha-\mathrm{MnO}_{2}$ and $\beta-\mathrm{MnO}_{2}$ at $\mathrm{pH}$ 4. This may result in their higher decolorization rates. Compared with tunnel structure of $\alpha-\mathrm{MnO}_{2}$ and $\beta-\mathrm{MnO}_{2}$, two-tunnel structured $\alpha-\mathrm{MnO}_{2}$ showed higher activity than the single-tunnel structured $\beta-\mathrm{MnO}_{2}$ due to the more exposure of $\mathrm{MnO}_{6}$ edges [17], although the $\beta-\mathrm{MnO}_{2}$ has a higher AOS (3.96). Moreover, the BET surface area of $\beta-\mathrm{MnO}_{2}$ is much smaller than that of $\alpha-\mathrm{MnO}_{2}$ and $\delta-\mathrm{MnO}_{2}$, which means higher crystallization degree for $\beta-\mathrm{MnO}_{2}$. Thus, the activation energy to break the crystal structure is more than that of $\alpha-\mathrm{MnO}_{2}$ and $\delta-\mathrm{MnO}_{2}$ during redox reactions. This may explain the lower oxidation capability of $\beta-\mathrm{MnO}_{2}$ for $\mathrm{RhB}$ at low $\mathrm{pH}$ solution.

The variation of the solution $\mathrm{pH}$ influenced the surface charge properties of the dye and the manganese oxides as well as their interactions. As shown in Scheme 1, the molecular of $\mathrm{RhB}$ contains carboxylic group and amino group. The carboxylic group exists in the protonated state by decreasing the solution $\mathrm{pH}$ beyond the $\mathrm{pK}_{\mathrm{S} 2}$ value, which corresponds to 3.22 , and the amino group is protonated only under very weakly basic conditions with the $\mathrm{pK}_{\mathrm{B}}$ value being 13.75 [18]. At $\mathrm{pH} \leq 3.22$, the positively charged lead manganese oxides surface interacts more attractively with the uncharged carboxylic acid than with the positively charged amino group. At $\mathrm{pH}>\mathrm{PZCs}$ of manganese oxides, the attractive interaction is established between the positively amino group and the negatively charged surface of manganese oxides. In our experiments, the decolorization efficiencies of $\mathrm{RhB}$ for the three manganese oxides all increased with decrease solution $\mathrm{pH}$, which could be attributed to the increase of the redox potential, electron transfer, and the surface charge density of $\mathrm{MnO}_{2}$ at lower $\mathrm{pH}$ values. Thus, the oxidation rate of $\mathrm{RhB}$ by the manganese oxides is dependent upon their physicochemical parameters, crystal structures, and solution $\mathrm{pHs}$.

\section{Reduction and dissolution of the synthetic manganese oxides by $\mathrm{RhB}$ dye}

The degradation of organic compounds by manganese oxides commonly accompany release of $\mathrm{Mn}$ (II) from reductive dissolution of manganese oxides [19, 20]. Figure 3 shows the dissolution behavior of the three manganese oxides with and without $\mathrm{RhB}$ at different $\mathrm{pH}$. When $\mathrm{pH}>\mathrm{PZC}\left(\mathrm{MnO}_{2}\right)$, only a small amount of released $\mathrm{Mn}$ (II) could been determined in the solutions, and the amount of $\mathrm{Mn}(\mathrm{II})$ with $\mathrm{RhB}$ treatments are closed to that of treatments without $\mathrm{RhB}$, indicating that $\mathrm{Mn}(\mathrm{II})$ is mainly derived from the manganese oxides through slightly dissolving or ion-exchanging by $\mathrm{H}^{+}$. When $\mathrm{pH}<\mathrm{PZC}\left(\mathrm{MnO}_{2}\right)$, the amount of released $\mathrm{Mn}(\mathrm{II})$ increased obviously with decreasing $\mathrm{pH}$, and the amount of released $\mathrm{Mn}(\mathrm{II})$ with $\mathrm{RhB}$ treatments are much higher than that of the treatments without $\mathrm{RhB}$, suggesting that the redox reaction occurs in the case of $\mathrm{pH}<\mathrm{PZC}$ $\left(\mathrm{MnO}_{2}\right)$. Moreover, it is observed that the amount of the released $\mathrm{Mn}(\mathrm{II})$ from $\delta-\mathrm{MnO}_{2}$ was much higher than that of $\alpha-\mathrm{MnO}_{2}$ and $\beta-\mathrm{MnO}_{2}$ at $\mathrm{pH}$ 2, which could attribute to the low AOS of Mn and the layered structures of $\delta-\mathrm{MnO}_{2}$ [7]. To investigate the components and structures of the residual manganese oxides, the XRD analysis was performed. The XRD patterns of the manganese oxides before and after duplicating the degradation reaction five times show no obvious differences, indicating that the unchanged structure of the manganese oxides after the surface oxidative degradation. These results demonstrate that the degradation of RhB dye dose not generate a new manganese oxide, and the $\mathrm{Mn}(\mathrm{III} / \mathrm{IV})$ is ultimately reduced to $\mathrm{Mn}(\mathrm{II})$ which is then released into the solution.

\section{Degradation mechanism of RhB by manganese oxides}

To explore the mechanisms of the $\mathrm{pH}$ and crystal type on the $\mathrm{RhB}$ removal using manganese oxides, 

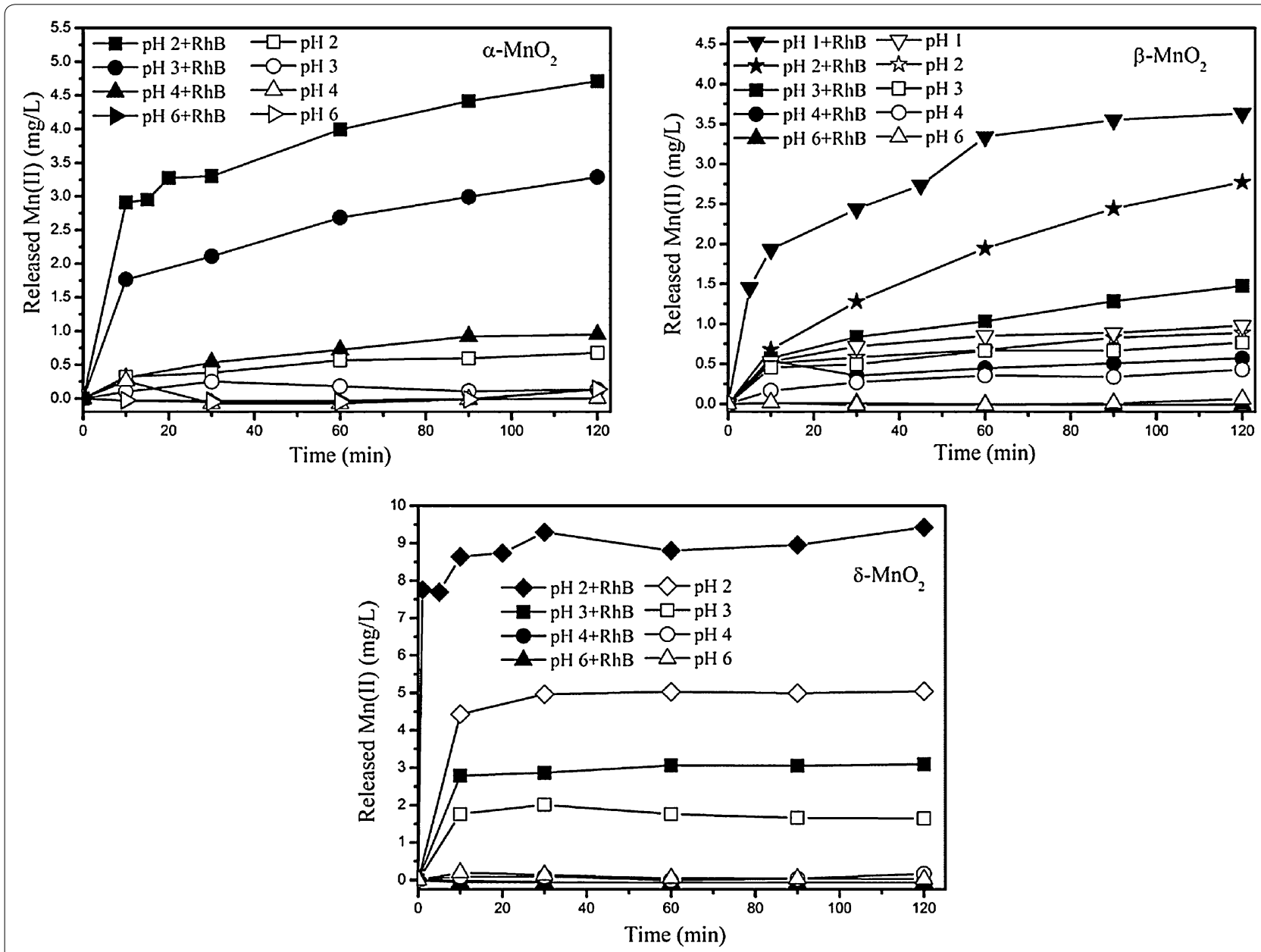

Fig. 3 Dissolution behavior of the manganese oxides with and without RhB at different $\mathrm{pH}$.

the intermediates of the reaction were analyzed using UPLC/MS technique. It is found that five peaks were observed at 3.05, 4.21, 4.70, 5.68, and $6.99 \mathrm{~min}$ in the UPLC/MS spectrum, which respectively correspond to the $\mathrm{m} / \mathrm{z}=331,359,387,443$, and 258 . The signal at $\mathrm{m} / \mathrm{z}=443$ could assign to the RhB parent ion [14]. The peaks at $\mathrm{m} / \mathrm{z}=387,359$, and 331 could refer to the formation of $N$-ehyl- $N^{\prime}$-ethyl-rhodamine 110 (MMRh), $\mathrm{N}$-ethyl-rhodamine 110 (MRh) and rhodamine $110(\mathrm{Rh})$ intermediates, which predicted by the cleavage of two, three, and four ethyl group from RhB molecule, respectively [21-24]. The appearance of a peak at $\mathrm{m} / \mathrm{z}=258$ could be due to cleavage of $-\mathrm{COOH}$ and $-\mathrm{CNH}_{2}$ from $\mathrm{Rh}(\mathrm{m} / \mathrm{z}=331)$. Additionally, the TOC concentration of the solution decreased from $18.2 \mathrm{mg} / \mathrm{L}$ of the initial solution to $2.3 \mathrm{mg} / \mathrm{L}$ of treatment for $\alpha-\mathrm{MnO}_{2}$ at $\mathrm{pH} 2$. Moreover, $\mathrm{NO}_{3}{ }^{-}$and $\mathrm{NH}_{4}{ }^{+}$could be detected in the treated solutions and the concentrations of them are 0.86 and $0.23 \mathrm{mg} / \mathrm{L}$, respectively. These results indicated that most of the RhB could be degraded completely by manganese oxides. Based on the above experimental observations, a plausible degradation mechanism of RhB was proposed (Additional file 1: Figure S6). It is suggested that the decolorization of $\mathrm{RhB}$ by manganese oxides consists of three main stages: (1) cleavage of the ethyl groups from $\mathrm{RhB}$ molecular to form Rh; (2) further destruction of $\mathrm{COOH}$ and $-\mathrm{CNH}_{2}$ from $\mathrm{Rh}$ to form the small molecular substances; (3) mineralization of the small molecular substances into $\mathrm{CO}_{2}, \mathrm{H}_{2} \mathrm{O}, \mathrm{NO}_{3}{ }^{-}$and $\mathrm{NH}_{4}{ }^{+}$.

The UPLC/MS data demonstrated that the peak intensities of consecutive products (at $\mathrm{m} / \mathrm{z}=387,359$, 331 , and 258) were first increased and then decreased gradually for $\alpha-\mathrm{MnO}_{2}$ treatment at $\mathrm{pH} 3$ and 4 (Fig. 4), indicating that the by-products formed under those conditions were unstable and finally degraded to a large extent. For comparison, the peak intensities of intermediates show a similar change for $\beta-\mathrm{MnO}_{2}$ and $\delta-\mathrm{MnO}_{2}$ at $\mathrm{pH} 1$ and pH 2, respectively (Fig. 4). However, the peak intensity of product (at $\mathrm{m} / \mathrm{z}=331$ ) gradually increased during reaction time at $\mathrm{pH} 2$ and $\mathrm{pH} 3$ 


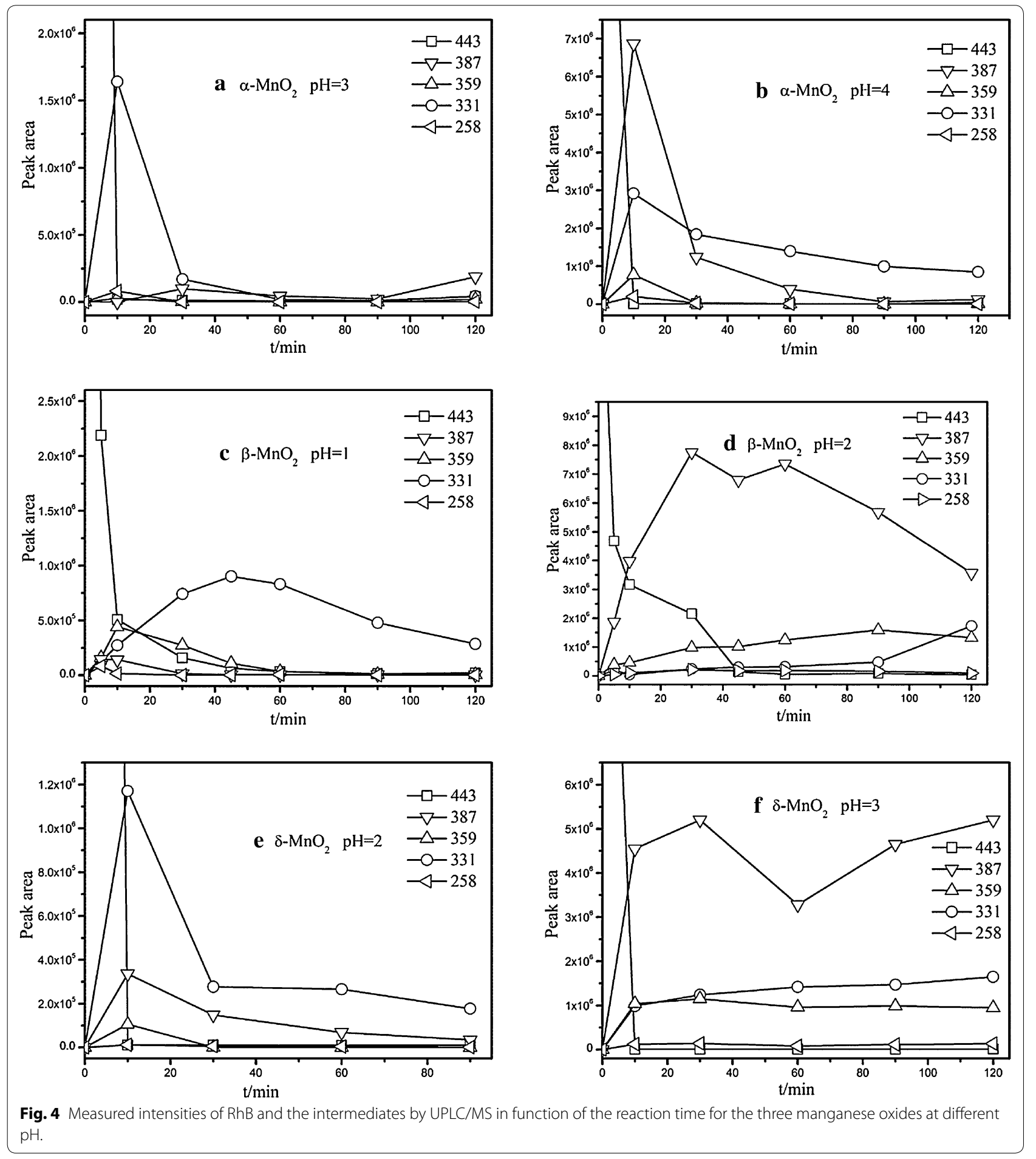

(Fig. 4), respectively, suggesting that RhB could not be degraded completely by $\beta-\mathrm{MnO}_{2}$ and $\delta-\mathrm{MnO}_{2}$. These results reveal that the degradation mechanisms of $\mathrm{RhB}$ by the manganese oxides depend on the $\mathrm{pH}$ and crystal type.

\section{Conclusions}

Three manganese oxides with different crystal type were prepared using reflux method to decolorize RhB in different $\mathrm{pH}$ solutions. The decolorization efficiencies of $\mathrm{RhB}$ for the three manganese oxides all increase with 
decrease solution pH. $\alpha-\mathrm{MnO}_{2}$ presented in needles and showed the highest activity for $\mathrm{RhB}$ degradation at $\mathrm{pH}$ 2-6. $\delta-\mathrm{MnO}_{2}$ and $\beta-\mathrm{MnO}_{2}$ had microsphere and rod-like form, respectively. These two manganese oxides showed activity to degrade $\mathrm{RhB}$ at $\mathrm{pH} 2-3$ and only exhibited a very low adsorption rate and adsorption capacity at $\mathrm{pH}$ 4-6. The redox reaction between manganese oxides and $\mathrm{RhB}$ result in dissolution of manganese oxides and release of $\mathrm{Mn}(\mathrm{II})$. The degradation of $\mathrm{RhB}$ by manganese oxides consists of three main stages: (1) cleavage of the ethyl groups from $\mathrm{RhB}$ molecular to form $\mathrm{Rh}$; (2) further destruction of $-\mathrm{COOH}$ and $-\mathrm{CNH}_{2}$ from $\mathrm{Rh}$ to form the small molecular substances; (3) mineralization of the small molecular substances into $\mathrm{CO}_{2}, \mathrm{H}_{2} \mathrm{O}, \mathrm{NO}_{3}{ }^{-}$ and $\mathrm{NH}_{4}{ }^{+}$. These results indicate that manganese oxides especially $\alpha-\mathrm{MnO}_{2}$ may have potential applications in degradation of dye pollutants.

\section{Methods}

\section{Preparation of the manganese oxides}

Cryptomelane $\left(\alpha-\mathrm{MnO}_{2}\right)$ was prepared through oxidation of $\mathrm{Mn}$ (II) by permanganate under refluxing condition [25]. Typically, $5.89 \mathrm{~g}$ of $\mathrm{KMnO}_{4}$ was dissolved in $100 \mathrm{~mL}$ of water and heated to boil, then a solution containing $8.8 \mathrm{~g}$ of $\mathrm{MnSO}_{4} \cdot \mathrm{H}_{2} \mathrm{O}$ and $3 \mathrm{~mL}$ of concentrated $\mathrm{HNO}_{3}$ was added to the boiling solution. The mixture solution was refluxed for $24 \mathrm{~h}$. The product was filtered, washed seven times with deionized water, and dried at $60^{\circ} \mathrm{C}$ for $24 \mathrm{~h}$.

Pyrolusite $\left(\beta-\mathrm{MnO}_{2}\right)$ was synthesized by refluxing process as reported in our previous work [12]. In a typical procedure, a mixture of $135 \mathrm{~mL} \mathrm{MnSO}_{4}$ solution $(1.75 \mathrm{~mol} / \mathrm{L})$ and $13.6 \mathrm{~mL}$ concentrated $\mathrm{HNO}_{3}(16 \mathrm{~mol} / \mathrm{L})$ was added quickly to $450 \mathrm{~mL}$ of boiled $\mathrm{KMnO}_{4}$ solution $(0.04 \mathrm{~mol} / \mathrm{L})$. The resultant dark brown slurry was refluxed for $36 \mathrm{~h}$, then filtered and washed with deionized water several times until the $\mathrm{pH}$ reached $\sim 7.0$. The final products were dried in an oven at $60^{\circ} \mathrm{C}$ for $24 \mathrm{~h}$.

Birnessite $\left(\delta-\mathrm{MnO}_{2}\right)$ was prepared by refluxing treatment of $\mathrm{KMnO}_{4}$ and $\mathrm{HCl}$ mixture solution [26]. In a typical synthesis, $45 \mathrm{~mL}$ of $6 \mathrm{~mol} / \mathrm{L} \mathrm{HCl}$ was added to $400 \mathrm{~mL}$ of boiled $\mathrm{KMnO}_{4}$ solution $(0.4 \mathrm{~mol} / \mathrm{L})$ at the rate of $0.7 \mathrm{~L} /$ min. The resultant dark brown slurry was refluxed for further $30 \mathrm{~min}$. After being aged at $60^{\circ} \mathrm{C}$ for $12 \mathrm{~h}$, the product was filtered, washed seven times with deionized water, and dried at $60^{\circ} \mathrm{C}$ for $24 \mathrm{~h}$.

\section{Characterization of the prepared manganese oxides}

X-ray powder diffraction (XRD) was carried out using a Bruker D8 ADVANCE X-ray diffractometer equipped with monochromated $\mathrm{Cu} \mathrm{K} \alpha$ radiation $(\lambda=0.1541 \mathrm{~nm})$ at a tube voltage of $40 \mathrm{kV}$ and a tube current of $40 \mathrm{~mA}$. Scanning electron microscopy (SEM) images were obtained with a Hitachi S-4800 emission scanning electron microscope. ASAP $2020 \mathrm{M}+\mathrm{C}$ instrument was used to measure the superficial area and micropore size distributions of the materials. Samples were degassed in a vacuum at $250^{\circ} \mathrm{C}$ for about $10 \mathrm{~h}$ to remove water and other physically adsorbed species. The $\mathrm{N}_{2}$ isothermal adsorption and desorption experiments were performed at relative pressures $\left(\mathrm{P} / \mathrm{P}_{0}\right)$ from $10^{-6}$ to 0.9916 and from 0.9916 to 0.047 , respectively. The $\zeta$-potential of manganese oxides were measured with an MALVERN ZEN 3600 electrophoretic light scattering spectrophotometer. The three manganese oxides dispersed into deionized water to form $0.5 \mathrm{~g} / \mathrm{L}$ suspension solution and then treat it with ultrasonic for $60 \mathrm{~min}$. Three suspension solutions were prefiltered through a $0.45 \mu \mathrm{m}$ pore mill filter. The values of $\zeta$-potential under different $\mathrm{pH}$ were measured.

The AOS of the three manganese oxide were measured by the oxalic acid-permanganate back-titration method. Briefly, $0.1 \mathrm{~g}$ of the samples were completely dissolved in $10 \mathrm{~mL}$ of $0.5 \mathrm{M} \mathrm{H}_{2} \mathrm{C}_{2} \mathrm{O}_{4}$ and $10 \mathrm{~mL}$ of $0.5 \mathrm{M} \mathrm{H}_{2} \mathrm{SO}_{4}$ to reduce all of the manganese to $\mathrm{Mn}^{2+}$. The extra $\mathrm{C}_{2} \mathrm{O}_{4}{ }^{2-}$ was determined by back-titration at $60^{\circ} \mathrm{C}$ with standardized $0.02 \mathrm{M} \mathrm{KMnO}_{4}$ solution. The AOS was calculated on the basis of both the titration result and the total amount of Mn determined by atomic absorption spectrophotometer (AAS) [27].

\section{Decolorization of RhB dye by the manganese oxides at various $\mathrm{pH}$}

The concentration of $\mathrm{RhB}$ solution was $10 \mathrm{mg} / \mathrm{L}$, and the dosage of manganese oxides is $0.5 \mathrm{~g} / \mathrm{L}$. The solution $\mathrm{pH}$ was adjusted to set value by $\mathrm{HCl}$ and $\mathrm{NaOH}$. The mixture was allowed to react in room temperature with continuous stirring. At given time intervals, an appropriate amount of suspension was taken out and quickly diluted the density to the point with distilled water. For optical absorption measurements, the diluted solution was immediately centrifuged at $12,000 \mathrm{rpm}$ for $10 \mathrm{~min}$ to remove the manganese oxide particles. The changes of absorptions at $554 \mathrm{~nm}$ were applied to identify the concentrations of RhB, using a Shimadzu UV-2450 UV-vis spectrophotometer. The released of $\mathrm{Mn}$ (II) in the solutions were analyzed by AAS.

$\mathrm{RhB}$ and the intermediates generated in the degradation process were analyzed with ultra performance liquid chromatography (UPLC) triple quadrupole mass spectrometry (TQMS). Chromatographic separation was performed on a Waters Acquity UPLC system with a Crestpak $\mathrm{C} 18 \mathrm{~S}$ column that was placed at $40^{\circ} \mathrm{C}$. The mobile phase was methanol/ultra pure water $(1: 1, \mathrm{v} / \mathrm{v})$ at a flow rate of $0.5 \mathrm{~mL} / \mathrm{min}$. The sample injection volume was $10 \mu \mathrm{L}$. Mass spectrometry analysis was conducted on a Waters Aquity TQ Detector with electro spray 
ionization (ESI). The total organic carbon concentration in solution was analyzed using TOC analyzer (Shimadzu, TOC-vwp).

\section{Additional file}

Additional file 1: The following additional data are availabe with the online version of this paper. Figures S1-S3. UV-visible absorbance spectra of RhB dye after different time intervals at various $\mathrm{pH}$ for $\alpha-\mathrm{MnO}_{2}$, $\beta-\mathrm{MnO}_{2}$ and $\delta-\mathrm{MnO}_{2}$. Figure S4. XRD patterns of the three manganese oxides before and after RhB bleaching. Figure S5. Ion chromatogram and Mass spectra of RhB intermediates. Figure S6. Degradation pathway of RhB by manganese oxides.

\section{Authors' contributions}

$\mathrm{HJC}$ and $\mathrm{HZH}$ carried out most of the analyses, interpreted the results and drafted the manuscript. BY and MLF designed the experiments and helped interpret and draft the manuscript. All authors read and approved the final manuscript.

\section{Author details}

${ }^{1}$ Institute of Urban Environment, Chinese Academy of Sciences, Xiamen 361021, China. ${ }^{2}$ College of Civil Engineering, Fuzhou University, Fuzhou 350116, China. ${ }^{3}$ College of Civil Engineering, Huaqiao University, Xiamen 361021, China.

\section{Acknowledgements}

This work was financially supported by National Natural Science Foundation of China (Nos. 41371244, and 51278481), Xiamen Science \& Technology Major Program (No. 3502Z20131018), and the National High Technology Research and Development Program ("863" Program) of China (No. 2012AA062606).

\section{Compliance with ethical guidelines}

\section{Competing interests}

The authors declare that they have no competing interests.

Received: 1 December 2014 Accepted: 29 June 2015

Published online: 25 July 2015

\section{References}

1. Carneiro PA, Umbuzeiro GA, Oliveira DP, Zanoni MVB (2010) Assessment of water contamination caused by a mutagenic textile effluent/dyehouse effluent bearing disperse dyes. J Hazard Mater 174:694-699

2. Singh K, Arora S (2011) Removal of synthetic textile dyes from wastewaters: a critical review on present treatment technologies. Crit Rev Environ Sci Technol 41:807-878

3. Mezohegyi G, van der Zee FP, Font J, Fortuny A, Fabregat A (2012) Towards advanced aqueous dye removal processes: a short review on the versatile role of activated carbon. J Environ Manag 102:148-164

4. Das M, Bhattacharyya KG (2014) Oxidation of Rhodamine B in aqueous medium in ambient conditions with raw and acid-activated $\mathrm{MnO}_{2}, \mathrm{NiO}$, ZnO as catalysts. J Mol Catal A Chem 391:121-129

5. Luo S, Duan L, Sun B, Wei M, Li X, Xu A (2015) Manganese oxide octahedral molecular sieve (OMS-2) as an effective catalyst for degradation of organic dyes in aqueous solutions in the presence of peroxymonosulfate. Appl Catal B Environ 164:92-99

6. Chen R, Yu J, Xiao W (2013) Hierarchically porous $\mathrm{MnO}_{2}$ microspheres with enhanced adsorption performance. J Mater Chem A 1:11682-11690

7. Remucal CK, Ginder-Vogel M (2014) A critical review of the reactivity of manganese oxides with organic contaminants. Environ Sci: Processes Impacts 16:1247-1266
8. Chen $\mathrm{H}, \mathrm{HeJ}$ (2008) Facile synthesis of monodisperse manganese oxide nanostructures and their application in water treatment. J Phys Chem C 112:17540-17545

9. Wang X, Mei L, Xing X, Liao L, Lv G, Li Z et al (2014) Mechanism and process of methylene blue degradation by manganese oxides under microwave irradiation. Appl Catal B: Environ 160-161:211-216

10. Lan B, Sun M, Lin T, Cheng G, Yu L, Peng S et al (2014) Ultra-long $\alpha-\mathrm{MnO}_{2}$ nanowires: control synthesis and its absorption activity. Mater Lett 121:234-237

11. Liu Y, Chen Z, Shek C-H, Wu CML, Lai JKL (2014) Hierarchical mesoporous $\mathrm{MnO}_{2}$ superstructures synthesized by soft-interface method and their catalytic performances. ACS Appl Mater Interfaces 6:9776-9784

12. Cui H-J, Huang H-Z, Fu M-L, Yuan B-L, Pearl W (2011) Facile synthesis and catalytic properties of single crystalline $\beta-\mathrm{MnO}_{2}$ nanorods. Catal Commun 12:1339-1343

13. Sui N, Duan Y, Jiao X, Chen D (2009) Large-scale preparation and catalytic properties of one-dimensional $\alpha / \beta-\mathrm{MnO}_{2}$ nanostructures. J Phys Chem $\mathrm{C}$ 113:8560-8565

14. Ahmed KAM, Li B, Tan B, Huang K (2013) Urchin-like cobalt incorporated manganese oxide OMS-2 hollow spheres: synthesis, characterization and catalytic degradation of RhB dye. Solid State Sci 15:66-72

15. Hao X, Zhao J, Zhao Y, Ma D, Lu Y, Guo J et al (2013) Mild aqueous synthesis of urchin-like $\mathrm{MnO}_{\mathrm{x}}$ hollow nanostructures and their properties for RhB degradation. Chem Eng J 229:134-143

16. Dang T-D, Cheney MA, Qian S, Joo SW, Min B-K (2013) A novel rapid onestep synthesis of manganese oxide nanoparticles at room temperature using poly(dimethylsiloxane). Ind Eng Chem Res 52:2750-2753

17. Saputra E, Muhammad S, Sun H, Ang HM, Tade MO, Wang S (2013) Different crystallographic one-dimensional $\mathrm{MnO}_{2}$ nanomaterials and their superior performance in catalytic phenol degradation. Environ Sci Technol 47:5882-5887

18. Merka O, Yarovyi V, Bahnemann DW, Wark M (2011) pH-control of the photocatalytic degradation mechanism of rhodamine $\mathrm{B}$ over $\mathrm{Pb}_{3} \mathrm{Nb}_{4} \mathrm{O}_{13}$. J Phys Chem C 115:8014-8023

19. Kuan W-H, Chan Y-C (2012) pH-dependent mechanisms of methylene blue reacting with tunneled manganese oxide pyrolusite. J Hazard Mater 239-240:152-159

20. Xu L, Li X, Ma J, Wen Y, Liu W (2014) Nano-MnO on activated carbon prepared by hydrothermal process for fast and highly efficient degradation of azo dyes. Appl Catal A General 485:91-98

21. Chen F, Zhao JC, Hidaka H (2003) Highly selective deethylation of rhodamine $\mathrm{B}$ : adsorption and photooxidation pathways of the dye on the $\mathrm{TiO}_{2} /$ $\mathrm{SiO}_{2}$ composite photocatalyst. Inter J Photoenergy 5:209-217

22. He Z, Sun C, Yang S, Ding Y, He H, Wang Z (2009) Photocatalytic degradation of rhodamine $\mathrm{B}$ by $\mathrm{Bi}_{2} \mathrm{WO}_{6}$ with electron accepting agent under microwave irradiation: mechanism and pathway. J Hazard Mater 162:1477-1486

23. Natarajan TS, Thomas M, Natarajan K, Bajaj HC, Tayade RJ (2011) Study on UV-LED/ $\mathrm{TiO}_{2}$ process for degradation of Rhodamine B dye. Chem Eng J 169:126-134

24. Yu K, Yang S, He H, Sun C, Gu C, Ju Y (2009) Visible light-driven photocatalytic degradation of rhodamine b over nabio ${ }_{3}$ : pathways and mechanism. J Phys Chem A 113:10024-10032

25. DeGuzman RN, Shen Y-F, Neth EJ, Suib SL, O'Young C-L, Levine S et al (1994) Synthesis and characterization of octahedral molecular sieves (OMS-2) having the hollandite structure. Chem Mater 6:815-821

26. Zhao W, Cui H, Liu F, Tan W, Feng X (2009) Relationship between $\mathrm{Pb}^{2+}$ adsorption and average $\mathrm{Mn}$ oxidation state in synthetic birnessites. Clays Clay Miner 57:513-520

27. Ulrich HJ, Stone AT (1989) Oxidation of chlorophenols adsorbed to manganese oxide surfaces. Environ Sci Technol 23:421-428 